\title{
DISTÂNCIA PSICOLÓGICA EM INTERNACIONALIZAÇÃO DE EMPRESAS: REFLEXÕES SOB O PONTO DE VISTA DO ESTRANGEIRO
}

\section{PSYCHOLOGICAL DISTANCE IN THE INTERNATIONALIZATION OF THE FIRM: REFLECTIONS ON THE FOREIGNER'S POINT OF VIEW}

\author{
Ana Celano \\ Doutora em Administração \\ Professora adjunta do quadro fixo no Mestrado em Administração do lbmec-RJ. \\ Rio de Janeiro, RJ, Brasil \\ E-mail: ana@francocelano.com.br \\ Yuna Fontoura \\ Doutoranda em Administração \\ Escola Brasileira de Administração Pública e de Empresas - EBAPE - Fundação Getulio Vargas - FGV. \\ Rio de Janeiro, RJ, Brasil \\ E-mail: yunareis@gmail.com \\ Eliane Maciel \\ Consultora da Franco Celano Comunicação Ltda. \\ Petrópolis, RJ, Brasil \\ E-mail: maciel.eliane@gmail.com
}

\section{RESUMO}

Estudos em Gestão Internacional indicam que a distância psicológica impacta o desempenho organizacional, afetando também a questão da identidade organizacional em empresas em processo de internacionalização. Neste sentido, a partir de uma abordagem qualitativa e interpretativista, o presente estudo teórico-empírico teve por objetivo problematizar o fenômeno ainda pouco explorado da distância psicológica a partir da visão dos empregados estrangeiros de uma organização transnacional brasileira do setor de energia. A pesquisa empírica com empregados estrangeiros foi efetuada na Argentina, Colômbia e Venezuela. Os resultados ressaltaram que os fatores ambientais (formação de blocos comerciais, regiões e imigração e contatos fronteiriços) não se aplicaram ao nosso objeto de pesquisa, pois, embora estes países possuam fortes processos migratórios com o país de origem da empresa internacionalizada (no caso, o Brasil), ainda assim, existe uma considerável distância psicológica entre os empregados desses países com a sua matriz.

Palavras-chave: Gestão Internacional. Internacionalização de Empresas. Distância Psicológica. Empregados Estrangeiros. Transnacional Brasileira.

\section{ABSTRACT}

Studies in International Management indicate that the psychological distance impacts organizational performance and also affect organizational identity in companies during the internationalization process of the firm. In this sense, from a qualitative and interpretive approach, this theoretical and empirical study aimed to discuss the still unexplored phenomenon of psychological distance from the view of foreign employees of a brazilian transnational organization in the energy sector. Empirical research with foreign executives was conducted in Argentina, Colombia and Venezuela. The results indicated that environmental factors (formation of trading blocs, regions and immigration, and border contacts) did not apply to our research object. Although these countries have strong migration processes with the international company's country of origin (in this case, Brazil), there is still considerable psychological distance among these countries' employees and the main office.

Keywords: International Management. Internationalization of the Firm. Psychological Distance. Foreign Employees. Brazilian Transnational. 


\section{INTRODUÇÃO}

É crescente o interesse em estudos voltados para processos de internacionalização de empresas diante de um contexto de globalização econômica no campo de Gestão Internacional (BARKEMA, BELL e PENNINGS, 1996; JOHANSON e VAHLNE, 1997; REZENDE e SERPA, 2008; RODRIGUES et al, 2012). Por sua vez, não se nota o mesmo crescimento no número de pesquisas voltadas para a questão da "distância psicológica", que de fato representa um desafio a ser enfrentado pelas empresas que passam por esses processos (ROCHA, 2005; EVANS, TREATGOLD e MAVODO, 2000; BLOMKVIST, DROGENDIJK, 2013).

Segundo Sttotinger e Schlegelmilch (1998, p. 54), existem indícios de que a distância psicológica impacta o desempenho organizacional, afetando também a questão da identidade organizacional em empresas em processo de internacionalização. Estes autores propõem que as "diferenças culturais foram identificadas como sendo a maior fonte potencial de problemas e conflitos em negócios internacionais".

Por outro lado, não existe um consenso em torno da mensuração e redução da distância psicológica, sobre a qual são apresentados conceitos mais ou menos semelhantes, como poderemos constatar na revisão da literatura que integra esse artigo. Assim, no sentido de contribuir para o aprofundamento e ampliação deste conceito e sua aplicabilidade, este artigo apresenta os resultados de uma pesquisa etnográfica realizada por duas das autoras entre 2006 e 2011, em nove países, com cerca de 200 empregadosi de uma empresa transnacional brasileira da área de energia.

A relevância do trabalho reside parcialmente no fato de não se encontrar na literatura muitas referências sobre o tema - e, principalmente, a constatação de que existe uma carência de informações consolidadas com foco no relacionamento entre a organização e seus empregados em unidades internacionais. Além disso, ao se analisar a frequência com que o tema da distância psicológica tem estado presente em discussões acadêmicas e em periódico científicos pode-se constatar uma significativa diminuição entre os anos de 2010 e 2015, o que por si só já justificaria em muito a retomada deste conceito e de sua discussão como uma possibilidade teórica que ainda deve ser problematizada pela área de negócios internacionais pelo potencial que apresenta em termos de alargamento das perspectivas hoje disponíveis para uso.

Assim, o objetivo desta pesquisa foi problematizar o fenômeno ainda pouco explorado da distância psicológica a partir da visão dos empregados estrangeiros de uma organização transnacional, ampliando o escopo do trabalho de Rocha $(2005 ; 2007)$, no qual a autora aborda apenas a distância psicológica dos executivos brasileiros em relação à expansão de negócios para mercados internacionais e não considera o caminho contrário desta mesma distância, ou seja, o sentimento que separa os empregados estrangeiros da matriz de sua empresa em outro país.

Primeiramente foi efetuada uma revisão de literatura contemplando a teoria de distância psicológica e fatores redutores desta distância. Em seguida, foi descrita a metodologia utilizada no artigo. Por fim, efetuase uma análise dos resultados obtidos e as considerações finais. 


\section{DISTÂNCIA PSICOLÓGICA}

O conceito de distância psicológica (ou distância psíquica) foi primeiramente definido por Johanson e Wiederscheim-Paul (1975, p. 307), como "fatores inibindo ou dificultando o fluxo de informações entre a firma e o mercado". Entretanto, o fenômeno da distância psicológica passou a ser mais profundamente analisado dentro da teoria sobre o processo de internacionalização postulado pela Escola de Uppsala (JOHANSON; VAHLNE, 1977). Nesta teoria, a escolha pelos mercados a serem priorizados no processo de internacionalização passam por um critério de seleção relacionado à distância psicológica que seus membros terão com estas localidades e suas culturas e valores (JOHANSON; VAHLNE, 1977, 1990). Desta forma, Johanson e Vahlne (1977, p. 24), conceituam este fenômeno como "a soma dos fatores inibindo o fluxo de informações do mercado e para o mercado".

Outras definições para o conceito também podem ser encontradas na literatura, como a de Kogut e Singh (1988, p. 413) que definiram o fenômeno como "o grau de desconhecimento de uma firma a respeito das características de um mercado estrangeiro". Já Ford (1984, p. 102) o caracterizou como "o grau em que normas e valores de duas empresas diferem dadas as suas características nacionais individuais". Boyacigiller (1990) sugere que os fatores que contribuem para a distância psicológica devem incluir a religião dominante, a linguagem de negócios, a forma de governo, o desenvolvimento econômico e os níveis de emigração. Por outro lado, Evans et al. (2000) sugerem que esta pode ser definida pelas práticas de linguagem, pelos negócios, pelos sistemas legais e políticos, pela educação, pelo desenvolvimento econômico, pela infraestrutura de marketing, assim como pela estrutura da indústria e cultura. Já Nordstrom e Vahlne (1994) a definem em relação aos fatores que previnem ou dificultam a aprendizagem da empresa e sua compreensão a respeito de um ambiente desconhecido.

Um conceito mais elaborado pode ser visto em Evans et al. (2000b, p. 375), onde se lê que a distância psicológica pode ser definida como "a distância entre o mercado doméstico e um mercado estrangeiro, resultante da percepção e do entendimento da existência de diferenças culturais e negociais entre os mesmos". Já Fletcher e Bohn (1998) descrevem a distância psicológica como sendo "esta vontade, ou a falta dela, de estabelecer negócios em mercados estrangeiros específicos". Para os autores (1998, p. 49), existe a consideração de que, embora a distância psicológica "inclua aspectos outros que não apenas a cultura, a mesma se baseia em percepções que são, senão inteiramente determinadas, no mínimo influenciadas culturalmente". Ou seja, para os autores, o fator cultural é imprescindível a este conceito.

Freitas (1997) reforça que a cultura organizacional, como espaço de relacionamento entre o indivíduo e a empresa, atua neste campo da distância psicológica, servindo como um ingrediente adicional que:

exerce o papel de agenciadora de sentidos e significados, atuando diretamente no imaginário, no coração do psiquismo dos indivíduos e desenvolvendo com ele uma relação de cumplicidade entre a organização e os desejos e medos inconscientes dos indivíduos que nela trabalham (FREITAS, 1997, p. 116). 
Desta forma, para o empregado estrangeiro de uma organização de outra nacionalidade, a identificação com a cultura desta empresa, ou a forma como acontece esta interação terá impacto direto sobre a formação de uma identidade organizacional internacional (CELANO, 2007).

Segundo Nkomo e Cox (2006), o fato dos indivíduos terem identidades múltiplas e não uma identidade única contribui para a complexidade da identidade nas organizações. Os indivíduos não são apenas africanos, europeus, coreanos, brancos, negros, mulheres, homens, gerentes de marketing ou gerentes de produção. As identidades se cruzam para criar uma identidade amalgamada. As maneiras pelas quais as identidades interagem são importantes para um contexto organizacional. Assim, o estudo de uma identidade envolve, necessariamente, atenção para com sua interação com outras identidades.

Ao mesmo tempo, deve-se evitar o essencialismo no tratamento da identidade, reconhecendo sua variabilidade. A identidade é construída socialmente e não inata. Pode ser mensurada nominalmente como propriedade objetiva de um indivíduo. Como Hall (1992) enfatiza, a identidade não é estável ou fixa, mas social e historicamente construída e sujeita a contradições, revisões e mudanças. Uma visão de construção social enfatiza o entendimento do processo por meio do qual as distinções de identidade emergem e tornamse visíveis aos indivíduos e grupos nas organizações.

Um ponto relevante concernente à questão da distância psicológica e de sua percepção no ambiente organizacional dentro do conceito da diversidade e da internacionalização foi apresentado por Adler (1997) como a "projeção da similaridade". Segundo essa teoria, as pessoas acreditam que as outras são sempre mais similares a elas do que na verdade o são. Projetar similaridades reflete um processo comum e natural. Professores norte-americanos pediram que gerentes de quatorze países descrevessem as metas e as rotinas de trabalho de seus colegas de empresa em outros países. Em todos os casos, os gerentes descreveram essas atividades como muito mais parecidas com as suas do que na realidade o eram. Projetar similaridades envolve assumir, imaginar e perceber similaridades quando existe diferença (ADLER, 1997). Entretanto, isto representa um processo prejudicial para as pessoas envolvidas em situações de comunicação intercultural. Desta forma, se assume que existe apenas uma maneira de ver o mundo, o que ocasiona mal entendidos constantes. É normal ver-se no ambiente organizacional comentários do tipo: "Eu o entendo perfeitamente, mas ele não consegue me entender" (grifo dos autores). Esse exemplo demonstra claramente o tipo de distorção sofrida no processo de comunicação.

Segundo Adler (1997), o processo de implementação de uma identidade globalizada e sinérgica deve ser cuidadoso. Antes de os membros da organização entenderem as necessidades de mudança baseados nesse pressuposto, eles devem desenvolver um autoconhecimento cultural, assim como o conhecimento das outras culturas envolvidas. Sem o conhecimento de algumas dessas dinâmicas envolvidas, muitas propostas de mudança e interação podem parecer absurdas. Com o aprofundamento do conhecimento cultural, a organização pode resolver problemas e implantar mudanças que levem a empresa a cumprir seus objetivos com mais eficiência.

É pertinente ressaltar que equipes de diferentes culturas, em geral, discordam de muitos significados, como a causa de eventos, a determinação de evidências admissíveis, a relevância de uma informação específica e possíveis conclusões que podem se desenhar. Em alguns casos, os desentendimentos permanecem implícitos ou camuflados, pois membros assumem que suas interpretações são similares quando na verdade o que acontece é o contrário. 
Além disso, realizando um levantamento recente sobre artigos publicados sobre o tema pode-se perceber que a perspectiva dominante acontece através do viés econômico, de conquista de mercados e dessa forma impregnado de relações assimétricas entre os diferentes atores envolvidos (LIBERMAN, FOSTER, 2009; TROPE, LIBERMAN, 2010; BLOMKVIST, DROGENDIJK, 2013).

Desta forma, muitos trabalhos assumem a existência de uma suposta homogeneidade cultural dentro de um país ou local específico (KOGUT; SINGH, 1988; BENITO; GRISPUD, 1992; FLETCHER; BOHN, 1998).

No entanto, esta premissa pode não estar correta, ou não deveria ser a única opção para análise dos fenômenos, uma vez que muitos países são formados por diferentes grupos étnicos ou desenvolveram regionalmente valores e diferentes tradições culturais (O'GRADY; LANE, 1996; JACK et al., 2008). Além disso, a própria globalização se incumbe de levar a diversidade em um nível bastante fragmentado para dentro das organizações, favorecendo uma análise individual do fenômeno, apenas, com considerações críticas sobre a influência externa e coletiva.

Dada a análise do conceito de distância psicológica e seus principais aspectos de interface como, por exemplo, a cultura local, verificaremos como este fenômeno pode ser percebido ou, até mesmo, reduzido, para uma melhor interação entre as partes (ex.: relação entre empresa transnacional e funcionários de sua filial no exterior).

\section{FATORES REDUTORES DA DISTÂNCIA PSICOLÓGICA}

Segundo Rocha (2005) não existe um consenso entre os diferentes autores em relação aos fatores medidores deste fenômeno. Além disto, há controvérsias se esta medição se daria a partir de uma visão individual ou coletiva (ou organizacional, ou nacional), o que representa um grande desafio para o campo (HALLÉN; WIEDERSCHEIM-PAUL, 1993). No entanto, o fenômeno da distância psicológica estará sempre, a priori, associado ao indivíduo, ao sujeito, à forma como uma pessoa vê e interpreta o mundo (FLECHTER; BOHN, 1998).

Por outro lado, na questão cultural, existem traços coletivos compartilhados pelos grupos e que, de certa maneira, funcionam como filtros que tendem a favorecer percepções semelhantes entre indivíduos, forçando uma sensação genérica de proximidade ou afastamento de outro país. Desta forma, a distância psicológica também é um fenômeno coletivo, relacionado ao conceito de etnocentrismo ou a uma forma comum e compartilhada de um grupo de pessoas que tem percepções semelhantes sobre outros grupos. Por esta razão, chama-se a cultura de "subjetividade coletiva" (CASSON, 1993; ROCHA, 2005; SILVA; ROCHA; FIGUEIREDO, 2007).

No caso das organizações - onde culturas específicas são desenvolvidas e exportadas, bem como adaptadas em maior ou menor grau em novas localidades, tanto nacionais como internacionais - as rotinas e traços característicos serão filtrados, interpretados e percebidos tanto de forma individual como coletiva pelos públicos de relacionamento (ERIKSSON et al., 2000). O que observamos neste processo é que esta interação e relacionamento exercem influência recíproca e terminam impactando em transformações e resistências que podem ser incorporadas à identidade organizacional e aos novos padrões de atuação, tanto nos indivíduos como nas empresas. 
Assim sendo, Rocha (2005) defende que a distância psicológica pode ser mensurada nos níveis individual, organizacional ou nacional. No caso específico deste artigo, que aborda a percepção de distância expressada pelos empregados de uma empresa transnacional, o nível individual merece especial atenção e análise, já que é por meio da percepção de cada empregado (cidadão, pertencente a um grupo nacional e local), que se dará sua interação com a organização.

Em pesquisa de campo efetuada com executivos de topo (presidente, dono e diretores) de 15 empresas brasileiras em seus primeiros esforços de internacionalização, Rocha (2005) verificou os elementos da distância psicológica (fatores que melhor explicam as diferenças e similaridades percebidas entre os mercados estrangeiros e o Brasil), bem como os mediadores de distância psicológica (fatores que podem diminuir a percepção de distância psicológica em relação à determinada cultura estrangeira por parte de outro grupo ou subgrupo cultural). Esta pesquisa era pautada na distância psicológica atuando sobre os executivos brasileiros e seus processos decisórios no momento de escolher os novos mercados, assim como seus relacionamentos com estes novos mercados.

No que se refere aos fatores redutores, estes foram classificados em quatro categorias (ROCHA, 2005): ambientais (formação de blocos comerciais, regiões e imigração e contatos fronteiriços); organizacionais (experiência efetiva no mercado estrangeiro ou em mercados similares, experiência internacional, planejamento, conexões para dentro); individuais (país de nascença, país adotivo, conhecimento de língua estrangeira, educação no exterior, viagens ao exterior); e; por fim; relacionais (contatos com firmas no país de origem, laços sociais com membros da indústria no exterior, alianças e parcerias estratégicas, disponibilidades locais de parceiros com a mesma bagagem cultural, transformação de locais em amigos, desenvolvimento de confiança, afinidade cultural).

Efetuada a pesquisa, a autora verificou que os fatores ambientais (blocos comerciais, regiões de imigração e contatos fronteiriços) afetaram as percepções nacionais de distância psicológica ou exerceram um impacto regional sobre estas. Os fatores relacionais foram os mais citados pelos executivos entrevistados. Já os fatores organizacionais tiveram menor importância do que a autora esperava (ROCHA, 2005).

Após esta etapa de fundamentação teórica, demonstraremos a metodologia estruturada para o artigo de forma a melhor compreendermos os dados analisados.

\section{METODOLOGIA}

Neste artigo, a coleta de dados se deu via método etnográfico. Embora não exista uma única possibilidade e definição de etnografia, destacamos que neste método:

o etnógrafo participando, aberta ou reservadamente, na atividade de um dado grupo por um extenso período de tempo, observando o que acontece, escutando o que é dito, fazendo perguntas - de fato, coletando todo tipo de dado disponível para iluminar assuntos e eventos que estão no foco de sua pesquisa. (HAMMERSLEY; ATKINSON, 1995, p.1) 
Deste modo, na etnografia faz-se necessário uma comunicação permanente entre o pesquisador, campo e seus membros. Fazem parte do processo de pesquisa, não apenas a subjetividade do pesquisador, mas também à daqueles que estão sendo estudados. Logo, tanto as reflexões do pesquisador sobre suas observações e ações no campo, como suas impressões e sentimentos, constituem-se como dados em si mesmos, passando a fazer parte também da interpretação (FLICK, 2004).

A coleta se deu, conforme destacada anteriormente na introdução, em uma empresa transnacional brasileira de energia presente em vinte e oito países do mundo e em quase toda a América do Sul, atuando em distribuição, exploração e refino de combustíveis e no setor de gás, no período de 2006 a 2011. Neste trabalho, foi possível acompanhar o dia-a-dia, interagir e observar mais de 200 empregados estrangeiros em nove unidades da empresa no exterior, não apenas nas suas sedes, mas também em diversos ativos que, via de regra, incluíam também os mais distantes de cada sede nacional, respectivamente.

Para a etapa de análise, a percepção de distância psicológica foi contemplada e melhor compreendida a partir da análise de desenhos elaborados individualmente pelos empregados, com materiais previamente disponibilizados (cola, papel, revista e canetas coloridas), expressando sua percepção da "distância entre o ponto geográfico em que estava e a sede, no Brasil". Na ocasião, os empregados buscaram expressar algo que foi chamado de "a distância" que ele experimentava em relação à matriz da empresa no Brasil.

A utilização de técnicas projetivas, como análise de desenhos, é um procedimento vantajoso em relação às técnicas tradicionais, uma vez que os desenhos permitem uma comunicação multidimensional com o campo de pesquisa (e não apenas unidimensional, como a fala, na entrevista), além de ultrapassarem a racionalidade e expressarem mais claramente as emoções. Embora a utilização de técnicas projetivas seja comum no campo da psicologia há praticamente um século, a adoção desse procedimento na análise de processos organizacionais é recente (ALCADIPANI; 2010). Porém, nas duas últimas décadas, a utilização deste recurso tem sido mais utilizada (BUCHANAN; 2001; DOUGHERTY; KUNDA, 1990; KUNTER; BELL, 2006; STRANGLEMAN, 2004; SYMON; CASSELL, 1998; ZUBOFF, 1988).

Ao final, pode-se voltar para a análise em profundidade de 5 (cinco) desenhos elaborados por trabalhadores argentinos, colombianos e venezuelanos que nos ajudaram a compreender a realidade organizacional e o fenômeno sob investigação (HAMMERSLEY; ATKINSON; 1995).

\section{ANÁLISE DOS RESULTADOS}

Por meio das representações gráficas e de desenhos realizados por empregados da empresa estudada em países sul americanos, foi efetuada a observação e a análise de como eram representadas as manifestações de distância psicológica existente sentida por estes sujeitos. Assim, a seguir serão apresentados os resultados representados pelos desenhos realizados por empregados da Argentina, Colômbia e Venezuela. 


\section{Pesquisa na Argentina}

Os desenhos 1, 2 e 3 foram obtidos na Argentina e fazem parte de uma amostra que inclui, originalmente, 49 (quarenta e nove) entrevistas semi estruturadas individuais, realizadas em cinco cidades: Buenos Aires, Rosário, Neuquém (região desértica ao norte da Patagônia), Santa Cruz e Rio Gallegos (as duas últimas localizadas no sul da Patagônia). O corpus de dados original incluiu a equipe diretiva da companhia na Argentina, agentes de comunicação e 37 entrevistas com empregados das áreas operacional e administrativa, em todos os tipos de negócios desenvolvidos pela companhia, naquele país.

A título de informação adicional, é importante ressaltar que os pesquisadores concluíram, após longa observação e análise de mais de 60 horas de entrevistas globais, que todo o extrato da pesquisa foi influenciado por dois fatores importantes, ambos ainda muito presentes até os dias atuais na Argentina, a saber:

a) A conjuntura macro-econômica, política e social vivida pelo país naquele momento, que era ainda de franco processo de reconstrução, após a grave recessão vivida a partir do final de 2001. Esta que foi uma das mais graves crises econômicas da história da nação argentina, deflagrada pelo fim da paridade peso-dólar americano, e exacerbou a pressão sobre o mercado de trabalho, como é possível verificar nos dados divulgados pelo órgão oficial responsável pelas pesquisas sociais direcionadas à Presidência da República. A crise argentina foi tão grave que, em apenas cinco meses - ou seja, de janeiro a maio de 2002 - 51,4\% da população caiu nos índices de pobreza extrema: até dezembro de 2001, este índice girava em torno de $40 \%$. Metade dos assalariados em idade produtiva só encontrava trabalho na economia informal. Em números absolutos, isso significava que o país que já fora um dos mais prósperos da América Latina, com índices de educação e qualidade de vida incomparáveis, nos anos 1960, contava com 18,2 milhões de pobres e 7,8 milhões de indigentes - mais da metade de sua população de 37 milhões. E na mesma ocasião, um em cada quatro argentinos encontrava-se desempregado (SIEMPRO, 2001; 2002).

b) A força de trabalho argentina - em especial, os empregados com mais de dez anos na empresa, que ocupavam cargos diretivos e que tinham forte identificação com a antiga cultura organizacional - ainda se ressentiam, no momento da entrevista, de um takeover classificado, por eles mesmos, como "extremamente frio e desrespeitoso, por parte da empresa anterior". Ao longo das entrevistas, a equipe de pesquisadores pode verificar que este processo - realizado em 2002, no auge da crise argentina - foi extremamente traumático e causador de desconfiança, além de gerador de mais resistência aos novos gestores, com sentimentos aguçados de temor e distanciamento. De fato, não houve qualquer comunicação para agradecer ou mesmo tranquilizar os empregados sobre o seu futuro imediato. 
Figura 1 - Primeiro desenho argentino

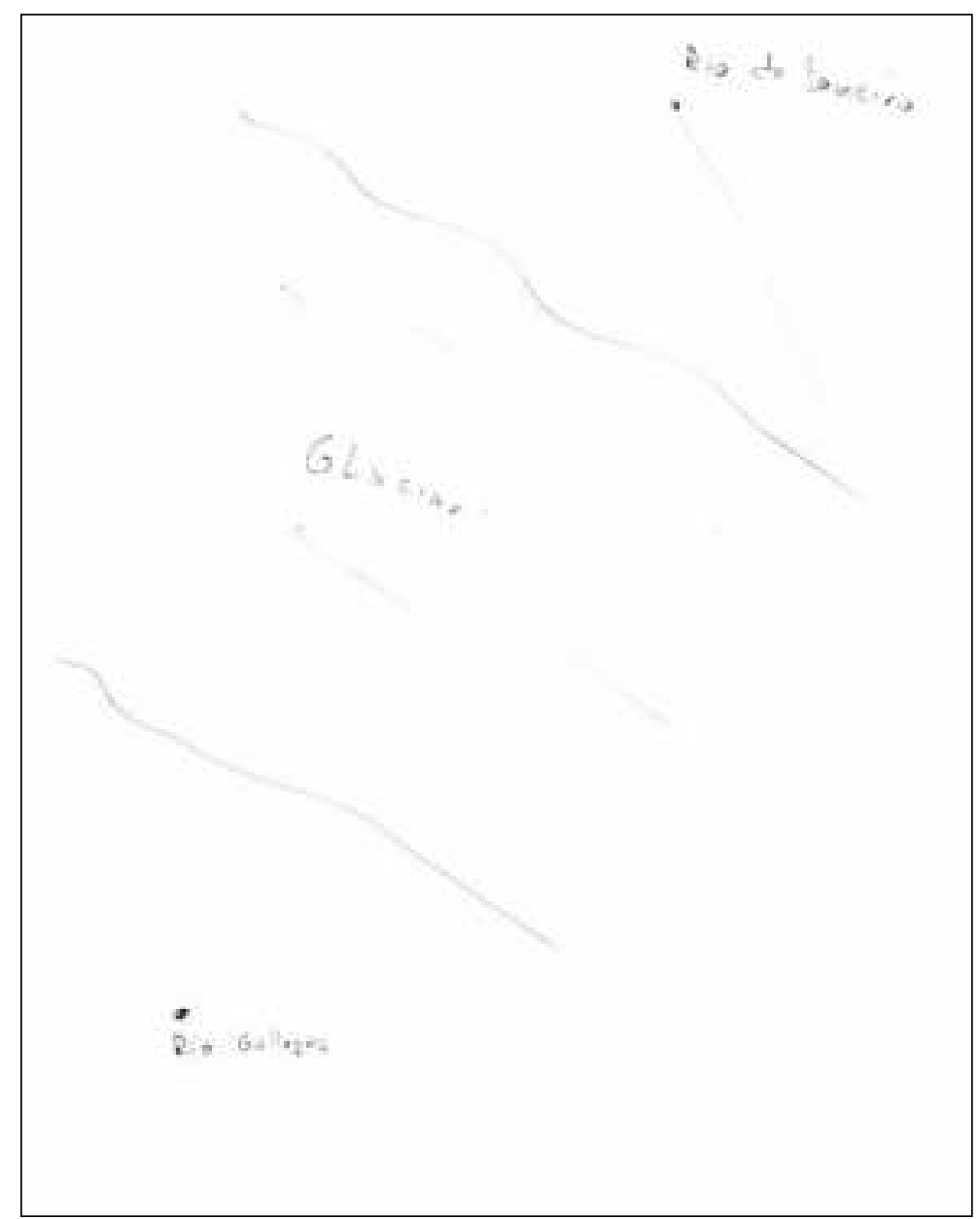

A figura 1 é uma representação de um empregado operacional do sul da Patagônia. Perguntado sobre a distância que ele imaginava existir entre a sua unidade de trabalho e a matriz da empresa no Brasil, ele desenhou uma linha sinuosa que corta a página na diagonal e escreveu: um "glaciar". Ora: os glaciares são, provavelmente, um dos aspectos topográficos mais característicos e relevantes na experiência vital do homem patagônico. Estas imensas barreiras de gelo são, na verdade, porções do Gran Campo de Hielo Patagônico - o maior manto de gelo do mundo, depois da Antártida - e que se divide, a rigor, em duas porções: o manto sul, que se estende ao largo de $350 \mathrm{~km}$ e cobre uma superfície total de $13.000 \mathrm{~km}^{2}$, e o manto da Argentina, que cobre $3.500 \mathrm{~km}^{2}$. Além de extensos, os extremos dos glaciares também se apresentam como imponentes paredões: o Glaciar Perito Moreno, que fica bem próximo da unidade de produção onde o entrevistado prestava serviços, é o maior deles e cobre $250 \mathrm{~km}^{2}$, com paredões que podem superar os 60 metros de altura. $\mathrm{E}$, o mais importante na representação: os glaciares nunca chegam a derreter totalmente. Mesmo que pequenas porções deles se desfaçam, no verão, a característica mais marcante destas enormes barreiras geladas é a sua permanência. Principalmente, o glaciar é virtualmente intransponível, porque imprevisível: não é possível domá-lo, cruzá-lo, dissolvê-lo, estabelecer pontes sobre ele (LOS GLACIARES, 2011).

Assim, quando este homem escolhe semelhante imagem para retratar a distância existente entre ele e a matriz da empresa onde trabalha, isto não é gratuito e não fala apenas de uma distância incalculável: o que ele oferece é a própria acepção do que, para ele, representam o gelo e a frieza das relações - a 
indiferença, em seu estado mais óbvio. Entre ele e a matriz, há um "gelo" imenso, portanto, que ele acredita que nunca poderá derreter ou atravessar. Nesta representação, de acordo com as dimensões propostas por Rocha (2005) estão presentes traços tanto individuais, quanto relacionais.

Da mesma forma, outras representações de distância psicológica podem ser notadas nos dois desenhos que se seguem, realizados por dois empregados de diferentes unidades na Argentina, ambos fora de Buenos Aires.

Figura 2 - Segundo desenho argentino

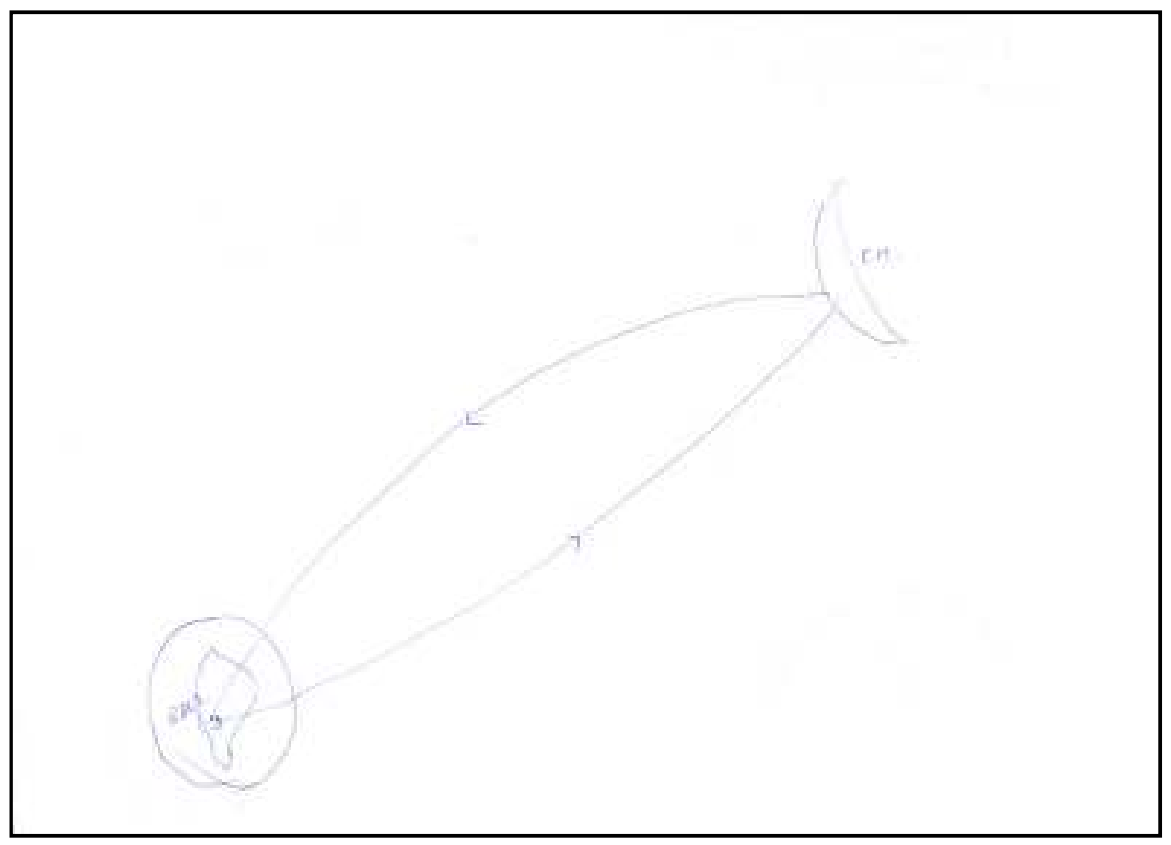

Figura 3 - Terceiro desenho argentino

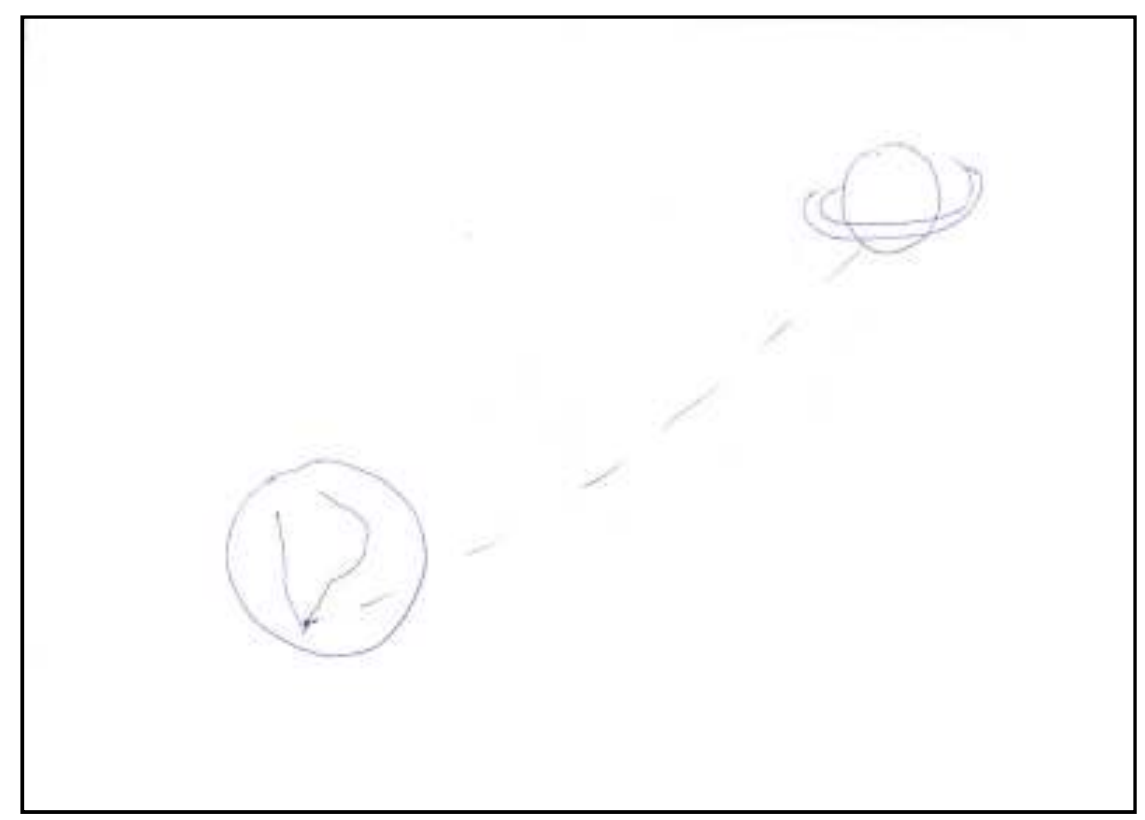


As figuras 2 e 3 retrataram a distância entre a unidade onde trabalham e a matriz com expressões que sugerem distâncias instransponíveis e total alienação. $O$ primeiro desenho foi realizado por um empregado da área técnica cuja unidade de trabalho se localiza a cerca de $280 \mathrm{~km}$ de Neuquén, em pleno deserto do Comahue. O segundo desenho, por um empregado da área operacional mais distante de Rio Gallegos, no extremo sul da Patagônia. Afastados um do outro por mais de $2.500 \mathrm{~km}$, ainda assim, ambos escolheram representações muito semelhantes: o primeiro retratou a distância entre a unidade onde trabalha e a matriz colocando a primeira na Terra e a segunda, na Lua; e o segundo colocou a unidade na Terra e a matriz em um planeta com anéis (provavelmente, Saturno). Assim, encontram-se novamente - e em duas regiões geográficas distantes entre si - representações da distância subjetiva entre a unidade de trabalho e a Matriz como aquela que separa os comuns dos mortais de um céu inatingível. Desta forma, as dimensões organizacionais, individuais e relacionais expostas por Rocha (2005) podem ser notadas nestas representações.

Há, porém, especificidades que podem ser analisadas apenas sob o ponto de vista da dimensão relacional (ROCHA, 2005). No primeiro desenho, a escolha da Lua como astro onde está a Matriz vem carregado de simbolismos: a Casa-Mãe é feminina (simbologia lunar), mas neste caso está distante e indiferente (a face côncava voltada para o outro lado) e é um centro de poder fálico, capitalista - não é, portanto, uma mãe acolhedora, mas castradora. Mais do que isso, o que está na Lua é sempre uma incógnita (o astro é um símbolo do mistério); ou a própria representação do imprevisível: não convém esquecer que 'lunático' é um termo comum ao português e ao espanhol que serve para designar o que é instável ou louco.

\section{Pesquisa na Colômbia}

O desenho 4 foi obtido na Colômbia. Na ocasião, foram realizadas 31 entrevistas individuais, com 19 empregados da área operacional e administrativa, seis gestores (gerentes e diretores), seis agentes de comunicação e o principal executivo da empresa, naquele país. Como nos demais países, os entrevistados foram distribuídos proporcionalmente entre a sede da empresa, em Bogotá, onde se concentrava o maior número de funcionários, e também em ativos nas localidades de Guando, Purificación e Yaguará, no Departamento de Huila, a cerca de $330 \mathrm{~km}$ da capital: este último escolhido por concentrar um número significativo de empregados à considerável distância e em uma área rural, qual seja, a cerca de $30 \mathrm{~km}$ da cidade histórica de Neiva. 
Figura 4 - Desenho colombiano

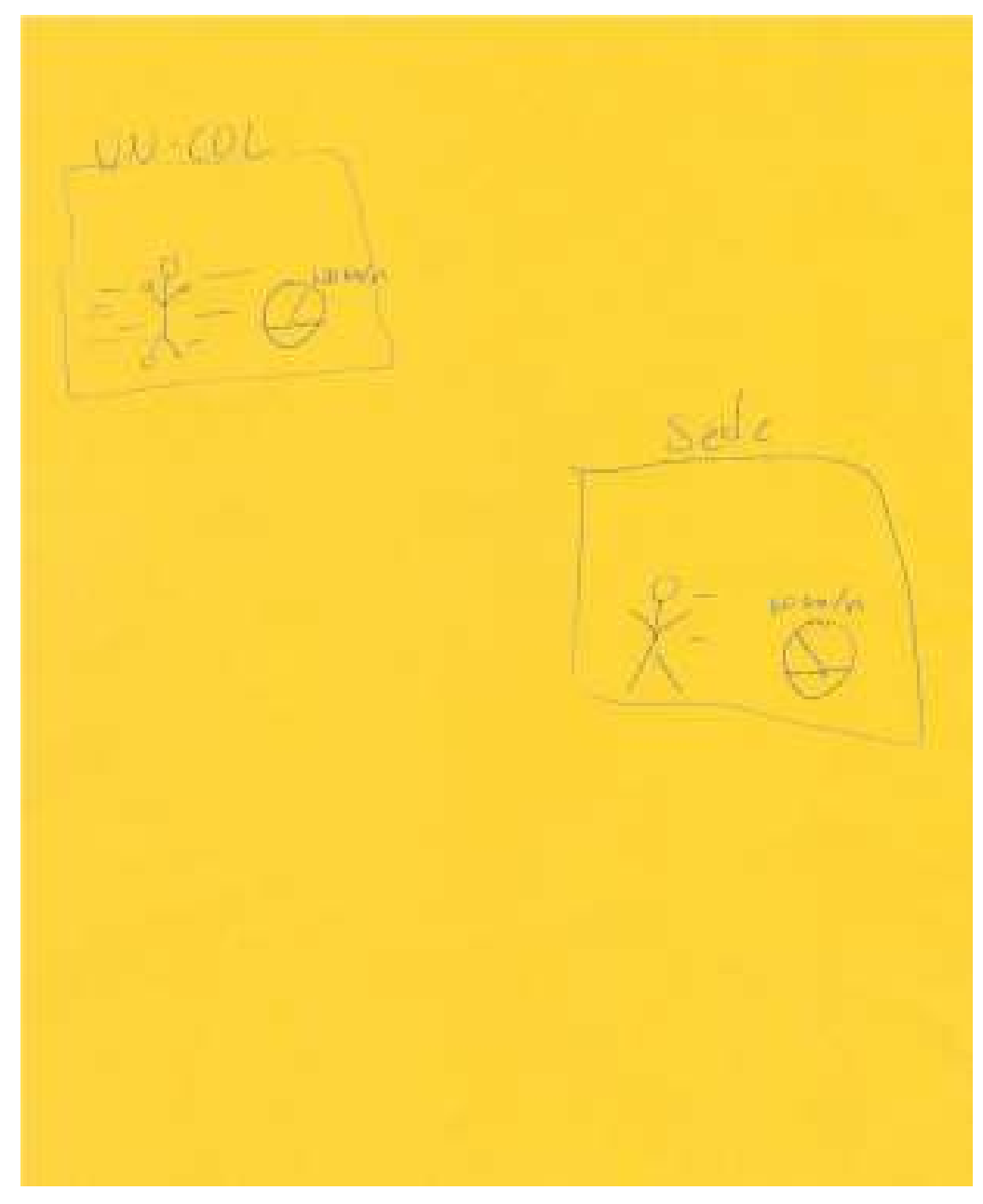

Ao retratar como é fazer parte desta empresa, o empregado colocou-se na Unidade Colômbia (com mãos e pés, porém sem olhos, ouvidos e boca) e com um velocímetro marcando $100 \mathrm{~km} / \mathrm{h}$, com vários riscos que sugerem velocidade. Paralelamente, há uma representação da Matriz (Brasil), como alguém sem mãos e pés e movendo-se a apenas $60 \mathrm{~km} / \mathrm{h}$. As duas estruturas estão desniveladas (a Colômbia acima) e funcionam em caixas fechadas, sem nenhuma inter-relação entre si. A ironia clara do desenho mostra a imagem que este empregado nutre da Matriz: uma estrutura lenta e burocrática, isolada em si mesma, que demora a dar respostas às solicitações das unidades e que também não dá valor à agilidade, empenho e juventude de seus empregados lotados nas unidades mais distantes. Por outro lado, este mesmo empregado demonstra um claro sentimento de superioridade em relação à sede (a representação da distância também destaca claramente a diferença de "altitude" entre Bogotá e Rio, o que pode ter muitas leituras). Neste sentido as dimensões ambientais, organizacionais e relacionais se fundem em uma primeira leitura (ROCHA, 2005).

Contudo há, na arrogância desta representação, um contraponto: sabemos que toda a manifestação de superioridade é, na verdade, uma manifestação defensiva que esconde um sentimento de insegurança e uma busca de aceitação (PERLS, 1981). Na representação das distâncias físicas, uma "veia" ou veio de ligação sai de Bogotá em direção ao Brasil, subterraneamente - mas o caminho não chega a se completar. 
Toda a produção do empregado indica, portanto, o desejo frustrado de integração e de mútua compreensão, conflito ao qual ele não reage pela submissão, mas pela insubordinação, pela ironia e pela denúncia.

\section{Pesquisa na Venezuela}

O desenho Venezuelano selecionado foi coletado na pesquisa realizada neste país com empregados lotados em unidades administrativas de Caracas e de produção, em Maracaibo. A amostra foi composta por 22 entrevistas, dos quais $77,3 \%$ realizadas em Caracas e $22,7 \%$, em Maracaibo.

\section{Figura 5 - Primeiro Desenho Venezuelano}

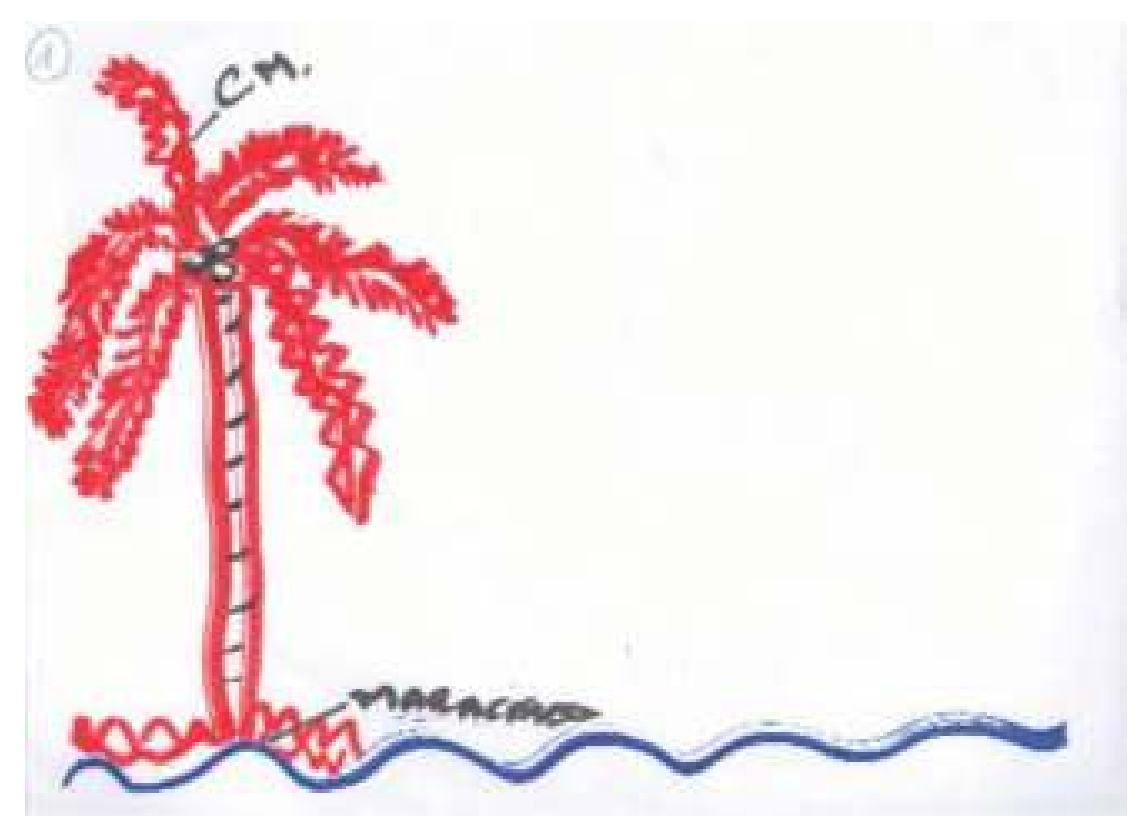

Sentimentos de agressividade e abandono aparecem na relação de distância (a matriz "longe demais" de suas raízes) e na cor atípica escolhida para traçar o coqueiro, que é vermelho e repleto de folhas com pontas agudas, sugerindo uma relação espinhosa, potencialmente capaz de trazer sofrimento. Esta empresa "vermelha", que dá o sustento à empregada, ainda assim a mantém numa posição funcional difícil, submetida - "espremida" junto ao chão - e com poucas perspectivas de visualizar outra posição menos sufocante nesta estrutura que ela vê como intensamente verticalizada, que só oferece a possibilidade de uma ascensão penosa, restrita a poucos: o tronco do coqueiro, dividido por riscos pretos, sugere quase uma "escada" estreita que sobe até os frutos desejados, numa profusão de "etapas", sem dúvida, muito difíceis de trilhar. É importante não esquecer que o fruto, no desenho, está identificado como a produção dos empregados.

Além da relação funcional difícil e excessivamente hierarquizada, o desenho da empregada de Maracaibo também parece indicar que a "empresa vermelha", expressa no coqueiro, espalha seu "modus operandi" também pelo ambiente em torno de si. Suas "raízes" também vermelhas - ondas curtas e instáveis com altos e baixos repetidos, como as encontradas nas transmissões de baixa freqüência - podem se referir 
aos efeitos que esta empresa provoca nos demais funcionários ou talvez na comunidade próxima. Porém, o que mais chama a atenção é que estas raízes estão de certa forma "prevalecendo", (colocando-se acima) da linha longa, em tom azul, que está abaixo: esta se irradia até mais longe e apresenta ondas mais suaves, sugerindo um chão mais fácil de trilhar ou um leito aquático que flui por baixo de tudo, provavelmente regando a árvore e oferecendo a ela sua força vital. Por fim, convém observar que a empregada, que está em Maracaibo - portanto, na base de tudo - vive num ponto de união entre o vermelho e o azul, uma área de interseção que sugere uma divisão de seus esforços profissionais entre duas lideranças díspares não apenas em seus objetivos, mas também em seus modelos de gestão.

Desta forma, as dimensões individuais, organizacionais e relacionais também se fazem presentes de forma absoluta na representação de distância psicológica destes desenhos. No entanto a dimensão relacional parece se destacar mais uma vez pela forma como se expressam, de forma inconsciente, os contatos entre as diferentes realidades, a percepção dos laços e as diferentes bagagens culturais envolvidas (ROCHA, 2005).

\section{CONSIDERAÇÕES FINAIS}

Como pode-se perceber no referencial teórico deste artigo, os conceitos e as teorias sobre a distância psicológica ainda se atém fortemente aos traços primários relacionados à expansão e dominação de mercados: a relação é muito mais enfática no que tange ao processo decisório dos executivos das empresas em processo de internacionalização, quando diante da escolha dos novos países para onde levar suas atividades. A própria pesquisa de Rocha $(2005 ; 2007)$ focou-se apenas na distância psicológica atuando sobre os executivos brasileiros e em seus processos decisórios, no momento da escolha de novos mercados, assim como em seus relacionamentos com estes novos mercados.

Porém, os resultados apresentados neste artigo levam a consideração que o modelo dominante para análise já não é suficiente nem para atender às empresas em processo de internacionalização, nem para abranger todas as vertentes possíveis do conceito de distância psicológica. Algumas variações importantes da pesquisa realizada nestes países nos dão esta dimensão, em especial, por três aspectos importantes:

a) A referida pesquisa já foi realizada após a efetiva internacionalização da empresa;

b) A pesquisa não se ateve ao ponto de vista daqueles que estavam no Brasil, no caso em questão, o país "exportador da cultura organizacional", como no caso de Rocha (2005; 2007). Ao contrário, toda a pesquisa foi realizada a partir do ponto de vista de quem está no exterior e é, na maioria das vezes, um empregado da nacionalidade local - de tal forma que há grandes possibilidades de maior percepção, da parte deste pesquisado, desta distância psicológica e de seus efeitos, no dia a dia. Verificou-se que isso também se dá no nível da gestão, ou seja, muitas vezes a sede não tem a mesma dimensão da distância psicológica que o escritório central do exterior, e que representa a matriz, localmente;

c) Por fim, a análise contemplou aspectos conjunturais, culturais, sócio-políticos e econômicos presentes naquele momento, nos países em questão, o que nos aproximou ainda mais da realidade sob análise. 
Desta forma, acredita-se que toda a abordagem de pesquisa sobre o fenômeno da distância psicológica já merece, atualmente, novas considerações e abordagens mais amplas e multidisciplinares. Logicamente, a distância psicológica continuará operando da forma anteriormente mapeada e com os mesmos atores, mas após o amadurecimento dos mercados e a expansão irreversível do processo de globalização, é possível que tenha acontecido um deslocamento e uma pulverização deste fenômeno que o leva a responder por muitas outras vertentes importantes para a gestão.

A partir do momento em que se tornou ponto pacífico que uma empresa, para sobreviver e manterse competitiva, deve considerar a proposição teórica de estender suas atividades para outros mercados, em outros países - e que este processo já se concluiu - as questões relacionais possíveis dentro deste espectro se tornam interligadas e de suma importância. A era da informação, que tornou o fenômeno da comunicação em rede um fato consumado, torna esta relação muito mais rápida, contínua, indissolúvel - e fundamental.

As considerações finais deste artigo levam à importância da adoção, pelas empresas em processo de internacionalização, de outros níveis de análise que incluam aspectos multidisciplinares, agregadores de valor para suas pesquisas como, por exemplo, o apresentado neste artigo. Acreditamos que estes elementos, se estrategicamente trabalhados, podem oferecer contribuições importantes para a tomada de decisões e para o estabelecimento de ações que efetivamente promovam o diálogo intercultural e a redução das barreiras que, se ignoradas, podem impactar no alcance dos resultados pretendidos.

No que tange aos fatores redutores da distância psicológica propostos por Rocha (2005), verifica-se, por meio dos desenhos analisados, que os fatores ambientais (formação de blocos comerciais, regiões e imigração e contatos fronteiriços) não se aplicam ao objeto da pesquisa em foco pois, embora a Argentina, a Venezuela e a Colômbia sejam regiões fronteiriças, com fortes processos migratórios com o país de origem da empresa internacionalizada e, no caso da Argentina, faça parte de um bloco comercial com o Brasil, ainda assim, existe uma considerável distância psicológica entre os empregados desses países com a sua matriz no Brasil.

Buscou-se, portanto, aprofundar esta reflexão, especialmente nos níveis diretivos das empresas em processo de internacionalização, na medida em que a pesquisa realizada deixa claro que meros fatores ambientais não se mostram aptos para reduzir a distância psicológica e seus impactos. Acreditamos também que mais pesquisas devem ser efetuadas a partir da distância psicológica dos executivos estrangeiros em relação à matriz de sua organização. Por fim, torna-se cada vez mais fundamental, para as empresas brasileiras que sofreram ou estão em processo de internacionalização, intensificar as pesquisas com sua força de trabalho internacional dentro deste foco ampliado, de maneira a obter mais segurança e assertividade em suas atividades. 


\section{REFERÊNCIAS}

ADLER, N. J. International dimensions of organizational behavior. South-Western College Publishing: Cincinnati, OH, p. 67-178, 1997.

ALCADIPANI, R. Violência e masculinidade nas relações de trabalho: imagens do campo em pesquisa etnográfica. Cadernos EBAPE.BR, v. 8, n. 1, Rio de Janeiro, Mar. 2010.

BARKEMA, H. G; BELL, J. H. J.; PENNINGS, J. M. Foreign entry, cultural barriers, and learning. Strategic Management Journal, v. 17, 151-166, 1996.

BAUER, M.; AARTS, B. A construção do corpus: um princípio para a coleta de dados qualitativos. In: BAUER, M.; GASKELL, G. Pesquisa Qualitativa com Texto, Imagem e Som. Petrópolis, RJ: Vozes, 2002.

BENITO, G. R. C.; GRISPUD, G. The expansion of foreign entry, cultural barriers, and learning. Strategic Management Journal, Hoboken, N.J., v. 17, n. 2, p. 209-31, 1993.

BLOMKVIST, K.; DROGENDIJK, R. The impact of psychic distance on Chinese outward direct investments. Management International Review. 53:659-686. 2013.

BOYACIGILLER, N. The role of expatriates in the management of interdependence. Journal of International Business Studies, v. 21, n. 3, 3rd Qtr., p. 357-381, 1990.

BUCHANAN, D. A. The role of photography in organization research: a reengineering case illustration. Journal of Management Inquiry, v. 10, n. 2, p. 151-164, 2001.

CALDAS, M.; TONELLI, M. J. Casamento, estupro ou dormindo com o inimigo? Interpretando imagens de fusões e aquisições. Organizações e Sociedade, Salvador, v. 9, n. 23, jan./abr. 2002.

CASSELL, C.; SYMON, G. Qualitative methods in organizational research: a practical guide. Londres: Sage, 1994.

CASSON, M. C. Cultural determinants of economic performance. Journal of Comparative Economics, Burlington, Mass., v. 17 , p. $418-442,1993$.

CELANO, A. C. O papel da comunicação interna da área internacional da Petrobras na América do Sul na formação de identidade organizacional. Dissertação de Mestrado. Universidade Estácio de Sá. Mestrado em Administração e Desenvolvimento Empresarial. Rio de Janeiro, 2007.

DOUGHERTY, D.; KUNDA, G. Photograph analysis: a method to capture organizational belief systems. In: GAGLIARDI, P. (Ed.). Symbols and artifacts: views of the corporate landscape. Berlin: De Gruyter, p. 185-206, 1990.

ERIKSSON, K. Effect of variation on knowledge accumulation in the internationalization process. International Studies of Management and Organization, New York, v. 30, n. 1, p. 26-44, 2000.

EVANS, J.; TREATGOLD, A.; MAVODO, F. T. Explaining export development through psych distance. International Marketing Review, London, v. 17, n. 2, p. 164-168, 2000.

FLETCHER, R.; BOHN, R. The impact of psych distance in the internationalization of the Australian firm. Journal of Global Marketing, New York, v. 12, n. 2, p. 47-68, 1998.

FLICK, U. Uma introdução à Pesquisa Qualitativa. Porto Alegre: Bookman, 2004.

FORD, D. Buyer/seller relationship in international industrial markets. Industrial Marketing Management, Amsterdam, v. 13 , n. 2, p. $101-113,1984$.

FREITAS. A. B. Traços brasileiros para uma análise organizacional. In: MOTTA F. P.; CALDAS, M. P. Cultura organizacional e cultura brasileira. São Paulo: Atlas, 1997.

HALL, S. The question of culture identity. In: HALL, S; HELD, D; McGREW, T. Modernity and its future. Cambridge: Polity, 1992.

HALLÉN, L.; WIEDERSCHEIM-PAUL, F. Psych distance and buyer-seller interaction. In: GHAURI, P. (Ed.) The internationalization of the firm: a reader. London: Harcourt, 1993.

LIBERMAN, N.; FÖRSTER, J. Distancing from experienced self: How global-versus-local perception affects estimation of psychological distance. Journal of Personality and Social Psychology, Vol 97(2), 203 -216. 2009.

JACK, G. A.; CALÁS, M. B.; NKOMO, S. M.; PELTONEN, T. Critique and International Management: An uneasy relationship? Academy of Management Review, v. 33, n. 4, p. 870-884, 2008.

JOHANSON, J.; VAHLNE, J. E. The mecanism of internationalization. International Marketing Review, London, v. 7, n. 4, p. 11-24, 1990.

JOHANSON, J.; VAHLNE, J. E. The internationalization process of the firm: a model of knowledge development and increasing foreign marketing commitments. Journal of International Business Studies, Basingstoke, v. 8, n. 1, p. 23-32, 1997. 
JOHANSON, J.; VAHLNE, J. E.; WIEDRSCHEIM-PAUL, F. The internationalization of the firm: four Swedish cases. Journal of Management Studies, Oxford, v. 12, n. 3, p. 305-322, Oct. 1975.

KOGUT, B.; SINGH, H. The effect of national culture on the choice of entry mode. Journal of International Business Studies, Basingstoke, v. 19, n. 3, p. 411-432, 1988.

KUNTER, A.; BELL, E. The promise and potential of visual organizational research. M@n@gement, v. 9, n. 3, p. 169189, 2006.

NKOMO, S. M.; COX, T. Diversidade e identidade nas organizações. In: CLEGG. S. R.; HARDY, C.; NORD, W. R. Handbook de Estudos Organizacionais - Modelos de análise e novas questões em estudos organizacionais, v. 1, São Paulo: Atlas, 2006.

NORDSTROM, K.; VAHLNE, J. E. Is the globe shrinking? Psychic distance and the establishment of Swedish sales subsidiaries during the last 100 years. In: M. LANDECK (Ed.) International trade: Regional and global issues, p. 41-56, New York: St Martin's Press, 1994.

O'GRADY, S.; LANE, H. The psychic distance paradox. Journal of International Business Studies. Basingstoke, v. 27, n. 2, p. 309-333, 1996.

PERLS, F. A abordagem Gestáltica e testemunha ocular da terapia. Rio de Janeiro. Zahar, 1981.

REZENDE, O.; SERPA, C. Internacionalização das empresas de biotecnologia em Belo Horizonte - MG, Brasil. Pretexto, v. 9, n. 3, p. 9-34, 2008.

ROCHA, A. O construto da distância psicológica: componentes, mediadores e assimetria. In: RODRIGUES, L. et al. Inovação aberta e internacionalização de negócio. Pretexto, v. 13, n. 3, p. 92-107, 2012.

HEMAIS, C. (Ed.) O Desafio dos Mercados Externo. Coleção de estudos COPPEAD, Ed. Mauá, 2005.

SILVA, J. R. G.; VERGARA, S. C.; O significado da mudança: as percepções dos funcionários de uma empresa brasileira diante da expectativa de privatização. Revista de Administração Pública, Rio de Janeiro, v. 34, n. 1, p. 79-99, 2000.

SILVA, M.; ROCHA, A.; FIGUEIREDO, O. Medindo o construto da distância psíquica. E\&G Economia e Gestão, Belo Horizonte, v. 7, n. 14, p. 1-178, 2007.

STÕTTINGER, B.; SCHLEGELMILCH, B. Explaining export development through psychic distance: enlightening or elusive? International Marketing Review, London, v. 15, n. 5, p. 357-72, 1998.

STRANGLEMAN, T. Ways of (not) seeing work: the visual as a blind spot. WES - Work, Employment and Society, v. 18, n. 1, p. 179-192, 2004.

SYMON, G.; CASSELL, C. Qualitative methods and analysis in organizational research, London: Sage, 1998.

TROPE, Y.; LIBERMAN, N. Construal-level theory of psychological distance. Psychological Review, Vol 117(2), 440-4, 2010.

WOOD JR, T.; CALDAS, M. P. Rindo do quê? Como consultores reagem ao humor crítico a sua profissão. O\&S Organizações \& Sociedade, v. 12, n. 34, p. 83-102, 2005.

ZUBOFF, S. In the age of smart machine: the future of work and power. New York: Basic Books, 1988.

' Forma como são chamados os funcionários pela organização sob estudo. 